\title{
Structure and Control of Flywheel Energy Converter
}

\author{
Yiming $\mathrm{He}^{\mathrm{a}}$, Xianyi Qian ${ }^{\mathrm{b}, *}$ \\ ${ }^{a}$ Changzhou Institute of Technology, CZU, Changzhou, China \\ ${ }^{b}$ School of Electronic Information \& Electric Engineering, Changzhou Institute of Technology, CZU, \\ Changzhou, China
}

\begin{abstract}
On the basis of the flywheel energy converter's structure in wind power turbine, we have used permanentmagnet synchronism motor as energy converter and built mathematical model. We have studied and realized control method of wind power turbine's constant output power. By analyzing the mathematical model, we have concluded that the needed time of stored energy is three times longer than constant torque control time, and the needed motor power is one second of constant torque control. When flywheel starts from zero speed to basic speed ( $\omega_{\max } / 5$ ), the constant torque control method will be acquired. When flywheel speeds up between $\omega_{\max } / 5$ and $\omega_{\max }$, the amplitude power control will be acquired. What we have studied is very important to realize constant output power.
\end{abstract}

Index Terms: Converter; Permanent-magnet Motor; Mathematical Model; Control Method

(C) 2011 Published by MECS Publisher. Selection and/or peer review under responsibility of the Research Association of Modern Education and Computer Science

\section{Flywheel Energy Converter}

The motor/generator in flywheel battery is a kind of integrated component which is used to convert energy, and it is called energy converter. When it is used as generator, it converts the electric power which from the mechanical energy into mechanical energy and stores in flywheel battery. And while it is used as generator, it converts the mechanical energy in flywheel battery into electric power by discharging.[1]

When flywheel battery is used as high-speed motor, it has such the characteristics as high-efficiency electrical motor and generator. Usually, it has such advantages as high torque and output power, long useful time, low no-load loss, high energy converting efficiency and good adaptability of speed changing. To flywheel battery, there are four kinds of motors in using: induction motor, switched reluctance motor, brushless permanent-magnet motor and permanent-magnet synchronism motor. Table 1 shows the several kinds of motors' main characteristics:

* Corresponding author:

E-mail address: hbxfqxyqxy_123@163.com 
Table 1. Comparison between several kinds of available motors' characteristics

\begin{tabular}{llll}
\hline Motor type & $\begin{array}{l}\text { Permanent-magnet } \\
\text { synchronism motor }\end{array}$ & AC induction motor & $\begin{array}{l}\text { Switched } \\
\text { reluctance motor }\end{array}$ \\
\hline Peak efficiency $(\%)$ & $95-97$ & $91-94$ & 90 \\
\hline Load efficiency $(\%)$ & $90-95$ & $93-94$ & $>15000$ \\
\hline Highest rotating speed(r $\cdot$ min-1) & $>30000$ & $900-15000$ & $1.5-4$ \\
\hline Relative cost of controller & 1 & $1-1.5$ & \\
\hline Immobility of motor & Good & Excellent & Excellent \\
\hline
\end{tabular}

Comparing with traditional DC motor, induction motor has many advantages: high efficiency, high energy density, low cost, high reliability. But also has such disadvantages as: low rotating speed and high rotor loss. The induction motors whose number of poles are less use large amount of copper and iron, which increase motors' weight.

Switched reluctance motor uses biconvex-pole structure. The stator uses integrated windings and the rotor hasn't excitation. So the rotor needn't any maintenance, and its structure is very firm. It is easy to realize switching of zero-current or zero-voltage. So it fits for wide-range rotating speed operation. But it has such disadvantages as high noise and its efficiency and power density are low by comparing with permanent-magnet motor.[2]

Brushless permanent-magnet DC motor converts excitation windings on the DC motor's rotor into permanent magnet, and the electric converter consists of solid state inverter and aaxis position monitor. The position sensor is used to monitor the position during the moving process of rotor, and it also converts position signal into electrical signal, which ensures every-phase windings' correct switching. Brushless permanentmagnet DC motor inputs square-wave current into motor's rotor directly, which controls the operation of brushless permanent-magnet DC motor. Its best advantage is that it has been removed the inverter and electric brush of traditional DC motor. So it has been removed all kinds defects which caused by electric brush's inverting. Its another advantage is that it can produce big electromagnetic torque when the current and counter EMF all reach the peak values because of the interaction between rectangular-wave current and rectangularwave magnetic field. On the other hand, it has radiator lamp which increases load density and power density.

Permanent-magnet synchronism motor is permanent-magnet AC synchronism motor whose synchronism motor's rotor excitation windings have been replaced by permanent magnet. We can get synchronism rotating magnetic pole by putting permanent magnet into rotor. We haven't used excitation windings and electric brush any more, and the inputted current is three-phase sine wave. This kind of motor has high energy density and efficiency, small volume, low cost and rapid response.

According to flywheel rotor's special structure, we can't produce salient pole on it, so it is impossible to use switched reluctance motor. Induction motor usually operates reliably at middle or low rotating speed, so it can't be used in flywheel. Brushless permanent-magnet DC motor's working magnetic field is step-by-step rotating magnetic field which produces torque pulsation with big noise. Permanent-magnet synchronism AC motor's working magnetic field is uniform rotating magnetic field whose torque pulsation is small, and its operating noise is small. On the other hand, it not only has such advantages as simple structure which likes AC motor, reliable operation and convenient maintenance, but also has such advantages as high operation efficiency, no excitation loss and wide speed regulation range. On the other hand, it is easy to control and realize two-way converting power. It is especially for flywheel battery, which used as energy converter. So, many countries usually use permanent-magnet synchronism AC motor as flywheel battery driving motor.

In order to reduce noise, we have designed a kind of permanent-magnet synchronism motor's outer rotor which is shown by Fig.1. In this kind of structure, the permanent magnet on the rotor is made by rare earth 
material, and it also has used Halbach array distribution manner which has formed uniform rotating magnetic field. The windings on the rotor use Litz wires. And we should try our best to reduce the cost of copper. This kind of structure has acquired the superposition of rotor's axes and stator's axes, which is convenient to seal vacuum container by putting cooling liquid circulators out of the vacuum.

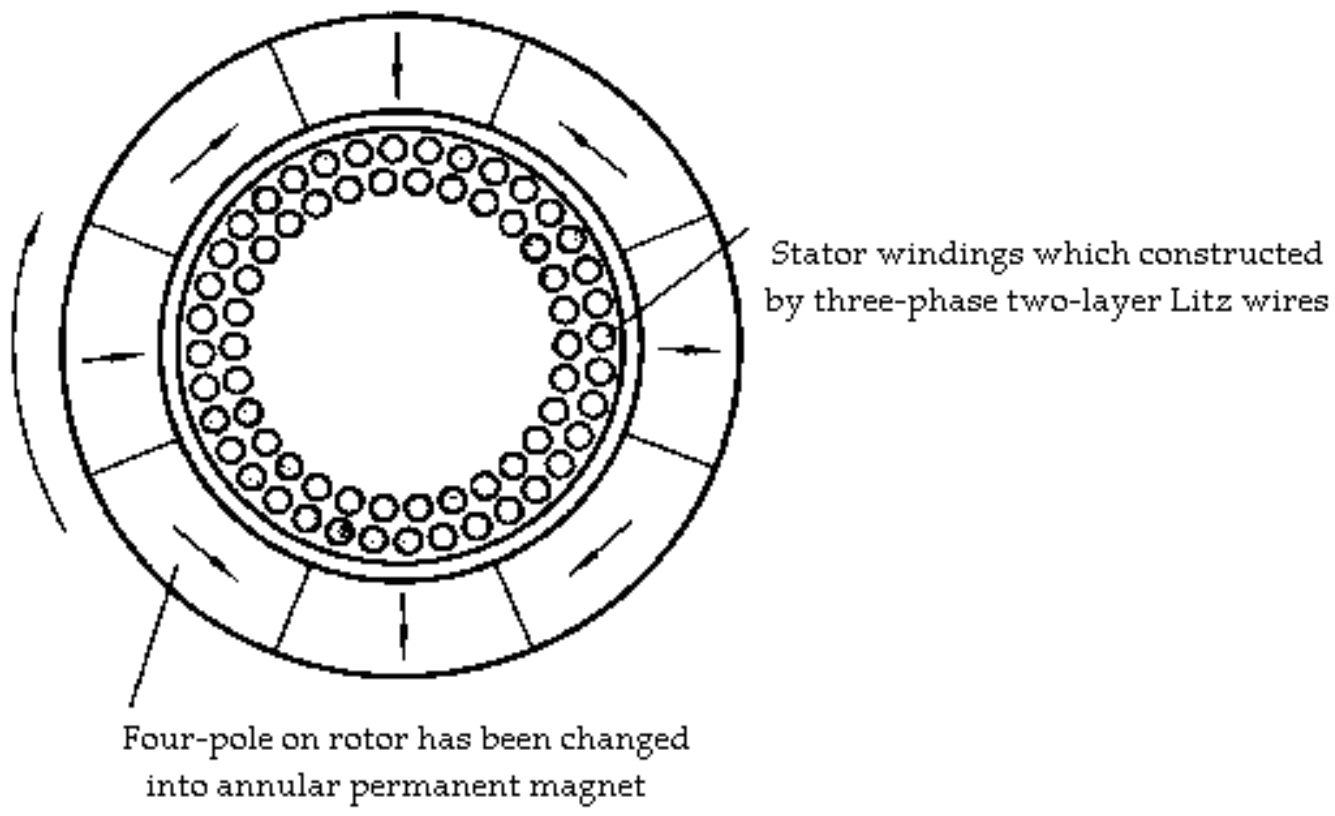

Fig. 1. Structure of permanent-magnetic synchronism motor's outer rotor

Halbach array is a kind of annular gradual changing magnet which consists of many pieces of small magnets, which can produce strong magnetic gap near annular magnet. It has been proposed by K1ausHalbach who was a physical scientist in Idwrcnce Befkeley laboratory. Halbach had prescribed all kinds of electromagnetic system's structures, such as two-pole, four-pole and six-pole. So we can calculate any point's magnetic field easily in air gap in accordance with annular regular changing magnetic field principle. And the calculating equation is:

$$
H \approx 1.57 M\left[\frac{1}{r_{1}}-\frac{1}{r_{2}}\right] r_{0}
$$

In this equation, $M$ represents the magnetization density of permanent magnet; $R_{2}$ represents external diameter of Halbach array; $r_{1}$ represents the inner diameter; $r_{0}$ represents the distance between magnetic field point and center of axis.

Once the magnetic field has been known, we can calculate all kinds of parameters of motor.

According to the energy converter which designed by Halbach array, there isn't any end load or unbalance torque on its suspended matter because we needn't fix any iron core or yoke. So the external leakage magnetic flux can be ignored, and there isn't any hysteresis loss and eddy current loss in stator. On the other hand, it doesn't need to use the gap of rotor and stator as key size to control. Flywheel battery has low idle speed loss and high efficiency eventually by using Litz wires as stator windings.[3] 


\section{Permanent-Magnet Synchronism Motor Mathematical Model}

The common method which used to analyze permanent-magnet synchronism motor which controlled by sinusoidal current is dq axis mathematical model. It is not only used to analyze sinusoidal current permanentmagnet synchronism motor's constant operating performance, but also the motor's instant performance.

In order to build the dq axis mathematical model of sinusoidal current permanent-magnet synchronism motor, we should notice that:

- Ignoring the saturation of motor iron core;

- Ignoring the eddy current and hysteresis loss;

- The motor's current must be the symmetrical three-phase sinusoidal current.

So, we can conclude the following equations:

Voltage equations:

$$
\begin{aligned}
& U_{d}=\frac{d \varphi_{d}}{d t}-\omega \varphi_{q}+R_{1} i_{d} \\
& U_{q}=\frac{d \varphi_{q}}{d t}-\omega \varphi_{d}+R_{1} i_{q} \\
& 0=\frac{d \varphi_{2 d}}{d t}+R_{2 d} i_{2 d} \\
& 0=\frac{d \varphi_{2 q}}{d t}+R_{2 q} i_{2 q}
\end{aligned}
$$

Flux linkage equations:

$$
\begin{aligned}
& \psi_{d}=L_{d} i_{d}+L_{m d} i_{2 d}+L_{m d} i_{f} \\
& \psi_{q}=L_{q} i_{q}+L_{m q} i_{2 q} \\
& \psi_{2 d}=L_{2 d} i_{d}+L_{m d} i_{2 d}+L_{m d} i_{f} \\
& \psi_{2 q}=L_{2 q} i_{q}+L_{m q} i_{2 q}+L_{m q} i_{2 q}
\end{aligned}
$$

Electromagnetic torque equation:

$$
T_{e m}=P\left(\psi_{d} i_{q}-\psi_{q} i_{d}\right)
$$


Mechanical motion equation:

$$
J \frac{d \Omega}{d t}=T_{e m}-T_{L}-R_{\Omega} \Omega
$$

In these equations, $\mathrm{U}$ represents voltage; $i$ represents current; $\psi$ represents flux linkage;

$d 、 q, 2 d, 2 q$ : Stator's subscript of $d$ and $q$ axis;

$L_{m d} 、 L_{m q}: d$ axis mutual inductance and $q$ axis mutual inductance between stator and rotor;

$L_{d}=L_{m d}+L_{1}, L_{q}=L_{m q}+L_{1}$;

$L_{2 d} 、 L_{2 q}: d$ axis mutual inductance and $q$ axis mutual inductance between stator and rotor; $L_{2 d}=L_{m d}+L_{2}, L_{2 q}=L_{m q}+L_{2}$;

$L_{1} 、 L_{2}: d$ eddy current inductance and $q$ eddy current inductance between stator and rotor;

$i_{f}$ : Equivalent excitation current of permanent magnet (A), and its value is a constant ( ${ }^{f}=\psi_{f} / L_{m d}$ ) when we needn't consider the affection of permanent magnet which caused by temperature.

$\psi_{f}$ : Flux linkage which caused by permanent magnet;

$J$ : Moment of inertia which includes the moment of inertia of rotor and the moment of inertia which converted by load;

$R_{\Omega}$ : Torque of load;

$T_{L}$ : Resisting force coefficient;

The connection between every variable in motor's $d$ axis and $q$ axis and the real every variable can be realized by means of coordinate. For example, we can use power-constant coordinate conversion when the motor's real three-phase currents of $i_{U}, i_{V}$ and $i_{W}$ are needed to be converted into $d q$ coordinate currents $i_{d}$ and $i_{q}$.

$$
i_{d}=\sqrt{\frac{2}{3}} i_{0}\left[\begin{array}{ccc}
\cos \theta & \cos \left(\theta-\frac{2 \pi}{3}\right) & \cos \left(\theta+\frac{2 \pi}{3}\right) \\
-\sin \theta & -\sin \left(\theta-\frac{2 \pi}{3}\right) & -\sin \left(\theta+\frac{2 \pi}{3}\right) \\
\sqrt{\frac{1}{2}} & \sqrt{\frac{1}{2}} & \sqrt{\frac{1}{2}}
\end{array}\right]\left[\begin{array}{l}
i_{U} \\
i_{V} \\
i_{W}
\end{array}\right]
$$

In equation (11), $\theta$ represents the position signal of motor's rotor. It is the angle between motor rotor's magnetic pole axes and stator's windings' axes; 
The parameter of $i_{0}$ represents the zero axis current, to three-phase synchronism system, the converted zero axis current $i_{0}$ is equal to zero.

To most of sinusoidal changing speed permanent-magnet synchronism motor, its rotor doesn't have damp windings, so the motor voltage equation and electromagnetic torque equation can be simplified.

\section{Control of Permanent-magnet Synchronism Motor}

\subsection{Method of permanent-magnet synchronism motor}

We can get motor torque and stator flux linkage by checking stator voltage and current and calculating the mathematical model of motor torque and flux linkage, which realizes the direct control of motor instant flux linkage and torque. We can combine motor and converter by means of this kind of control method.[4] So we can avoid the conversion of coordinate rotating, which simplifies the control system structure and increases the dynamic response speed of system. The stator flux linkage model of motor is that:

$$
\begin{aligned}
& \psi_{I \alpha}=\int\left(u_{I \alpha}-R_{I} \cdot i_{I \alpha}\right) \cdot d t \\
& \psi_{1,3}=\int\left(u_{I \beta}-R_{I} \cdot i_{I \beta}\right) \cdot d t
\end{aligned}
$$

The model of torque is that:

$$
T_{\alpha}=P_{u} \cdot\left(i_{1,3} \psi_{I \alpha}-i_{I \alpha} \psi_{1,3}\right)
$$

\subsection{Control of flywheel battery}

The charging process of flywheel is the process of accelerating motor. We require that the system has high speed as soon as it can during the process of charging. And we can use two kinds of frequency conversion control methods to speed up motor: constant-torque control and constant-power control. Constant-torque control method realizes the purpose on the basis of the maximal torque which the system can load, and the acceleration torque is invariable during the whole process. Constant-power control is based on the maximal power which the system can load, and the acceleration power of system is invariable.[5]

Supposed the ratio between flywheel rotor's maximal rotating speed and minimal rotating speed is 5:1, and then about $96 \%$ of total flywheel stored energy can be utilized. And the angular velocity of motor will vary from $\omega / 5$ to $\omega$. According to the constant-torque control method, the motor's maximal power and the acceleration time are:

$$
\begin{aligned}
& P_{\max }=T \omega \\
& t_{L}=\frac{J \omega-J(\omega / 5)}{T}-\frac{4 J \omega}{5 T}
\end{aligned}
$$

According to the constant-power control method, the motor power and acceleration time are: 


$$
\begin{aligned}
& P_{2}=T(\omega / 5) \\
& t_{2}=\frac{\Delta E}{P}=\frac{J \omega^{2} / 2-J(\omega / 5)^{2} / 2}{T(\omega / 5)}=\frac{12 J \omega}{5 T}
\end{aligned}
$$

In these two equations (18) and (19), the parameter of T represents the motor's electromagnetic torque; the parameter of $\mathrm{J}$ represents the total moment of inertia of flywheel axis.

\section{Conclusions}

We can conclude that the needed storage time which controlled by constant-power is three times than the method of constant-torque by comparing the equations from (16) to (19). So the needed motor power is one second of the method by using constant-torque. According to the analysis, the basic speed of flywheel battery is one fifth of normal rotating speed. When flywheel starts from zero speed to $\omega_{\max } / 5$, we should use constanttorque method to control; and we use amplitude-power to control when the flywheel accelerates between $\omega_{\max } / 5$ and $\omega_{\max }$.

\section{Acknowledgements}

We are very grateful to the Jiangsu Province College Natural Science Foundation of China for the support.

\section{References}

[1] LI Dong-dong CHEN Chen, WIND SPEED MODEL FOR DYNAMIC SIMULATION OF WIND POWER GENERATION SYSTEM[J], PROCEEDINGS OF THE CHINESE SOCIETY FOR ELECTRICAL ENGINEERING, 2005 25(21)

[2] ZHAO Wenzhen, QIN Lixue, Modeling Research of MW Wind Turbine Variable Pitch System[J], MACHINE TOOL \& HYDRAULICS, 2006(6)

[3] Sun Tao, VOLTAGE FLUCTUATION AND FLICKER CAUSED BY WIND POWER GENERATION[J], POWER SYSTEM TECHNOLOGY, 2003 27(12)

[4] Lin Yonggang Xu Li Li Wei, Semi-physical Simulation Test-bed for Electro-hydraulic Proportional Pitchcontrolled Wind Turbine System[J], CHINA MECHANICAL ENGINEERING, 2005 16(8)

[5] Huang Keyuan, INVESTIGATION OF A MATRIX CONVERTER-EXCITED VARIABLE-SPEED CONSTANT-FREQUENCY WI ND-POWER GENERATION SYSTEM[J], PROCEEDINGS OF THE CHINESE SOCIETY FOR ELECTRICAL ENGINEERING, 2002 22(11) 